\section{Class of behaviour}

Tim Roper

Social Behaviour in Mammals. By $\mathrm{T}$. Poole. Blackie/Chapman \& Hall: 1985. Pp.248. Pbk £13.95, \$22.50.

IT Is unusual nowadays to find a book on animal social behaviour that deals with a single taxonomic group or that arranges its subject matter on a taxonomic basis. The reason for this is simply that most recent work on social behaviour has revolved around functional questions, which often cross phylogenetic boundaries. A few taxonomic groups, such as the social insects, are specialized enough to be discussed as functional entities. But this is unlikely to be true of the class Mammalia. Can anything general but non-trivial be said about a group of species as diverse, in all respects, as shrews, elephants, bats, whales and humans?

The tension between ecology and phylogeny is evident in Trevor Poole's book, and is not successfully resolved. Poole begins with a brief summary of basic sociobiology and then deals in successive chapters with communication, reproduction, competition and resource exploitation. These are functional chapter headings, but the material within the chapters is often (but not always) arranged phylogenetically. Finally there is an orderby-order summary of social behaviour in mammals, starting with monotremes and ending with hominids.

The writing is clear enough but is factual rather than inspirational in tone, and has suffered from the need to compress so much information into a mere 200 pages. Because underlying principles tend to get lost in a mass of examples, I doubt whether the book will really inspire undergraduates. On the other hand, it is not a very satisfactory sourcebook either. Intricate lines of research and complex theoretical questions have had to be summarized in a sentence or two, and although in some places the references are surprisingly complete in others they are absent entirely.

Poole's book does remind the reader what enormous diversity there is within the mammals, and it corrects the common assumption that the only mammals whose social behaviour is at all interesting are the primates. It does not, however, convince me that mammalian social behaviour is a valid field in its own right, either for research or as the subject of an elementary textbook.

Tim Roper is a Lecturer in the School of Biology, University of Sussex, Brighton BNI 9QG, UK.

- A review of four general textbooks on animal behaviour will appear in the Nature issue of 10 April.

\section{Jolly impressive on primatology}

\section{J.R. Anderson}

The Evolution of Primate Behavior, 2nd Edn. By Alison Jolly. Macmillan/Collier Macmillan:1985. Pp.526. \$24.95, £20.

Although it has remained useful and popular, the 1972 edition of Alison Jolly's textbook was showing its age. For some time, students have had to look elsewhere for information on developments in primate ecology, sociobiology and psychology. The long-awaited second edition of The Evolution of Primate Behavior now makes life easier. Like its precursor, the book provides a scholarly and wideranging survey of current research in primate behaviour, in an informal style that will be widely appreciated.

Comparisons with the first edition are instructive. Certain earlier conclusions have not been borne out (for example Jolly acknowledges that the data now available do not indicate any strong relationship between folivory and territoriality in primates), while other questions raised in 1972 have been answered positively: thus we now know that non-human primates indeed show a similar progression through the stages of sensorimotor intelligence to that seen in human beings. Elsewhere, some topics that were in fashion in 1972 now get less space. Species differences in aggression, and environmental influences on aggression drop out (although competition between individuals and groups remains an important theme); the differen-

\section{Underlying action}

\section{Felicity A. Huntingford}

Essentials of Behaviour Genetics. By David A. Hay. Blackwell Scientific:1985. Pp.359. Pbk £15.80, \$27.

Essentials of Behaviour Genetics is an authoritative and valuable book. The introductory and concluding chapters provide interesting accounts of the history and probable future directions of the subject, but the book's particular strength is in its careful discussion of techniques for identifying genetic influences on behaviour and the mechanisms by which such influences act. These are illustrated with reference to different genetic mechanisms (from single locus mutants and detectable chromosome anomalies to polygenic systems) and different aspects of behaviour (from courtship and habitat selection to learning and personality traits). tial rearing experiments of the 1960 s are described quite briefly; and "attention structure" doesn't even make it into the new index. These will not be badly missed, given the coverage of topics of current interest that were virtually non-existent in primatology 15 years ago, such as the influence of plant secondary compounds on feeding, social awareness and deception, kin recognition, reciprocal altruism and adjustment of sex ratios of offspring.

As in the first edition, the chapters on intelligence are among the strongest. Here again there are some changes of emphasis in the author's summaries of the recent literature on tool-use, linguistic abilities and "cognition". Developments in ape language research are described at length, as are Piagetian approaches to cognition. Correspondingly, the treatment of other laboratory techniques seems brief or is missing (for example crossmodal matching, delayed response and its variants, serial position functions).

One unfortunate feature of the new edition is the many bibliographical errors: over 50 references cited in the text are missing from the bibliography, and there is a remarkable number of mismatches between dates in the text and bibliography. However, this will not unduly worry undergraduates looking for an up-to-date and readable account of the field. There are better recent books on some of the subjects discussed by Jolly, but, as a single textbook covering the spectrum of modern behavioural primatology, this is the best there is.

J.R. Anderson is Maitre-Assistant Associe in the Laboratoire de Psychophysiologie, Université Louis Pasteur, 7 rue de l'Université, 67000 Strasbourg, France.

Many different aspects of behaviour genetics are explored, including its relevance to other disciplines such as psychology and sociobiology, and its implications for our understanding of evolution. Hay also gives informed consideration to the social implications of the subject, in particular those of research into the inheritance of IQ. His extensive use of quotations helps to give a balanced picture of a highly controversial topic.

The book is not without its weaknesses. In particular, I question whether it is entirely suitable for its intended audience, which is defined in the preface as advanced students in psychology and genetics. Recognizing the disparate needs of these two groups, Hay introduces the psychologists to genetics by discussing the inheritance of mental retardation. For students whose background is in modern genetics, behaviour is treated as a particularly challenging phenotype for genetic research.

Neither of these good ideas quite works out in practice. The introductory chapter 